Perancangan Konfigurasi Struktur Tower dan Pembuatan Bilah Komposit (Sandwich)

\title{
PERANCANGAN KONFIGURASI STRUKTUR TOWER \\ DAN PEMBUATAN BILAH KOMPOSIT (SANDWICH) \\ UNTUK APLIKASI TURBIN ANGIN
}

\author{
Hendrix Noviyanto Firmansyah ${ }^{1}$, M Ardi Cahyono ${ }^{2}$ \\ Prodi Teknik Penerbangan \\ Sekolah Tinggi Teknologi Adisutjipto \\ Jalan Janti Blok R Lanud Adisutjipto, Yogyakarta \\ ${ }^{1}$ firmansyah.hendrix@gmail.com, ${ }^{2}$ total_sacrifice@yahoo.com
}

\begin{abstract}
Tower is a structure vertically designed that the blades and other components attached. The process for structural design for the tower starts by identifying all of the requirements, and then specifies the desired design criteria. The desired design criteria are high strength, low cost, lightweight, does not require a large area, ease of assembly and transport. The proposed tower types are guyed, lattice, and tubular. The analysis result shows that the lattice tower type matches with the design criteria. The next processes are modeling and stress analyzing using MSC Patran/Nastran. The maximum stress is 42 Newton per milimeters square and the Margin of safety $(M S)$ value is 7.815 , so the structure is safe. In the process of making the composite sandwich wind blades, it is starts with the creation of the master molding, mold, foam cores and assembly. The results of the three blades were made indicate by a difference in weight. It is caused by the manufacturing system (manual). However, the difference is still relevant or good because it is less than 5 percent.
\end{abstract}

Keywords: wind turbine, tower, lattice, composite, sandwich, Patran/Nastran.

\begin{abstract}
Abstrak
Tower merupakan sebuah struktur yang didesain vertikal sebagai tempat bilah dan komponen yang lainnya. Proses perancangan struktur tower dimulai dengan mengidentifikasi semua kebutuhan dan kemudian baru memberikan kriteria disain yang diinginkan. Kriteria desain yang dimunculkan adalah kuat, biaya yang murah, ringan, tidak membutuhkan lahan yang besar, mudah dalam transportasi dan pemasangan. Jenis tower yang diusulkan adalah jenis guyed, lattice, dan tubular. Hasil analisis menunjukkan bahwa jenis lattice yang cocok dengan kriteria rancangan yang diinginkan. Proses selanjutnya adalah memodelkan dan analisis tegangan dengan menggunakan MSC Patran/Nastran. Nilai tegangan maksimum hasil analisis menunjukkan 42 Newton per milimeter kuadrat, dan nilai MS sebesar 7,815 sehingga struktur tersebut aman. Pada proses pembuatan bilah komposit sandwich diawali dengan pembuatan master molding, cetakan, foam core, dan assembly. Hasil ketiga bilah yang dibuat menunjukkan adanya perbedaan berat. Perbedaan tersebut dikarenakan metode pembuatan yang masih manual. Namun hasilnya tergolong baik karena perbedaan masing-masing bilah sangat kecil, yaitu kurang dari 5 persen.
\end{abstract}

Kata kunci: wind turbine, tower, lattice, composite, sandwich, Patran/Nastran. 


\section{Pendahuluan}

Tower merupakan struktur yang menjulang tinggi (berdiri vertikal) untuk meletakkan bilah dan komponen yang lainnya agar bisa menggerakkan bilah sehingga akan memutar generator untuk menghasilkan listrik. Proses perancangan untuk konfigurasi struktur tower turbin angin haruslah dilakukan dengan benar dan sistematis agar sesuai dengan yang diharapkan. Selain merancang konfigurasi struktur tower, pada penelitian ini juga dilakukan pembuatan bilah angin komposit (sandwich) dilakukan dengan menggunakan metode hand layup dan vakum. Penelitian ini bertujuan untuk:

1. Membuat rancangan konfigurasi struktur tower

2. Melakukan pemilihan konfigurasi struktur tower yang sesuai dengan desain kriteria

3. Membuat 3 buah bilah komposit (sandwich).

Pada penelitian pemilihan jenis tower didasarkan kajian literatur dan survey lapangan dengan melihat contoh struktur yang relevan. Beban yang digunakan diasumsikan sesuai dengan kondisi pembebanan struktur saat operasi yaitu beban thrust, beban angin, beban mati (beban struktur)

\section{Tinjauan Pustaka}

Tower merupakan struktur yang berdiri vertikal yang dibunakan untuk menahan beban nacelle, bilah, hub, dan beban akibat variasi terpaan angin. Dengan melihat beban yang diterima oleh tower, maka stuktur tower haruslah kuat. Struktur tower yang digunakan pada turbin angin sangat bervariasi.

Menurut Cracks (2012), dalam "in onshore wind power", tower terdiri atas 5 jenis yaitu: Guyed Tower, Lattice Tower, Tubular tower, Hybrid Concrete and Tubular Steel Tower, dan Ferro-Concrete Tubular Tower.

Jenis beban yang terjadi pada tower terdiri atas beban mati, beban hidup, beban angin, dan beban gempa. Beban mati merupakan beban yang dimiliki oleh tower berupa beban konstruksi sendiri dan material pendukungnya. Beban hidup merupakan beban yang diterima tower atau tower dari operator yang bekerja pada tower tersebut baik pada saat perawatan maupun perbaikan. Beban angin merupakan beban alami yang akan selalu ada. Beban angin diperoleh dari tekanan udara yang ada disekeliling tower atau tower. Beban angin dipengaruhi oleh posisi dan tempat kedudukan tower. Beban gempa merupakan beban yang terjadi akibat adanya pegerakan tanah atau bumi disekitar konstruksi tower. 


\section{Metode Penelitian}

Secara umum urutan penelitian ini diawali dengan perancangan konfigurasi struktur tower yang meliputi memunculkan rancangan konfigurasi struktur tower. Selain itu dilakukan pemilihan jenis material, beban, dan kondisi batas. Langkah selanjutnya adalah analisis rancangan konfigurasi struktur tower yang akan dipilih untuk dimodelkan dan dianalisis tegangannya. Untuk pembuatan bilah komposit meliputi persiapan alat dan bahan, proses pembuatan, dan evaluasi kesesuaian.

\subsection{Pemilihan Konfigurasi Turbin}

Kriteria rancangan konfigurasi struktur tower yang diinginkan pada penelitian ini adalah sebagai berikut:

1. Kemampuan tower mensupport operasi turbin angin.

2. Biaya tower (cost) yang murah meliputi biaya materi tower, biaya pembuatan, dan biaya perawatan.

3. Berat tower yang relatif ringan dengan struktur yang tidak kompleks.

4. Proses assembly dan perawatan yang mudah.

5. Kemudahan transportasi dari tempat produksi ke tempat pemasangan.

Berdasarkan hasil survey materi, tempat produksi, dan tempat pemasangan, maka dalam penelitian ini dibatasi pada tiga model tower yaitu model guyed, lattice, dan tubular.

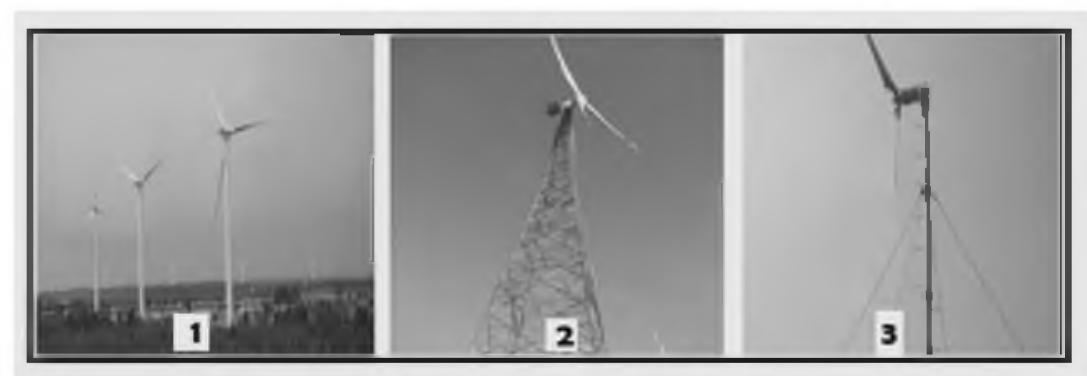

Gambar 1. Jenis tower yang akan dibandingkan (1. Tubular, 2. Lattice, dan 3. Guyed)

Untuk mempermudah analisis pemilihan konfigurasi maka perbandingan ketiga tower akan disusun menggunakan tabel 1 .

Tabel 1. Perbandiangan kriteria struktur tower

\begin{tabular}{|c|c|c|c|c|c|c|}
\hline $\begin{array}{l}\text { Mhatel } \\
\text { Towgr }\end{array}$ & Katrhtrlpustl & Botont & Assembly & Traspotasi & 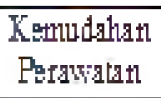 & $\begin{array}{l}\text { Kebunhatl } \\
\text { Laharl }\end{array}$ \\
\hline Gungd & Kocil & inteatl & & & Sulit & Sentrpit: \\
\hline$L d \mathrm{dicg}$ & Sedgrte & Sedgne & Bhidath & Thidght & Mhath & Setrlpit \\
\hline Tubwar & Besgr & Berat & Sullit & Sulit & Mith & Luas \\
\hline
\end{tabular}


Karena biaya (cost) terdiri atas biaya materi properti, pembuatan, dan perawatan maka akan dibuat tabel tersendiri sebagai berikut:

Tabel 2. Perbandingan Biaya Tower

\begin{tabular}{|c|c|c|c|}
\hline Midel & \multicolumn{3}{|c|}{ Binya } \\
\hline Towgr & Thlaterti Bahath & Penteratant & Pridatatatl \\
\hline Guged & Throgh & Mhrath & 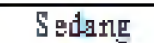 \\
\hline Latifor & Mhirath & M.Furath & 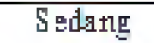 \\
\hline TUजे & Whal & Maght & What \\
\hline
\end{tabular}

Untuk membantu membuat keputusan, dibuatlah sistem pembobotan sederhana yang mana hasil pembobotan variabel dapat dilihat pada tabel 3 .

Tabel 3. Pembobotan variabel

\begin{tabular}{|c|c|c|c|c|c|c|c|c|c|c|}
\hline Model Tower & Kenampuath & Bobot & Assembly & Traspottasi & $\begin{array}{l}\text { Kemudahan } \\
\text { Perawatan }\end{array}$ & \begin{tabular}{|c|} 
Kebutthanar \\
Lahan
\end{tabular} & MateriBathat & $\mid \begin{array}{c}\text { Biaya } \\
\text { Pembuatant }\end{array}$ & $\begin{array}{c}\text { Biaya } \\
\text { Perawatant }\end{array}$ & Total \\
\hline Guyed & 1 & & & & 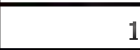 & 3 & 3 & 3 & & 21 \\
\hline Lattice & 2 & & & & & 3 & 3 & 3 & & 24 \\
\hline Tubular & 3 & & & & 3 & 1 & 1 & 1 & & 13 \\
\hline
\end{tabular}

Keterangan :

\begin{tabular}{|c|c|c|c|c|}
\hline bobot harga & & bobot betal struk ure & & botot kemampant \\
\hline trutalh & 3 & rittẹtatl & 3 & besar \\
\hline 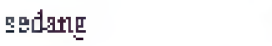 & 2 & gagdang & 2 & ged-1.titg \\
\hline mahal & I & terat & 1 & kscil \\
\hline botort ketutuhan lahas & & botort kemudahan Perawatar & & \\
\hline sempit & 3 & minutsh & 3 & \\
\hline 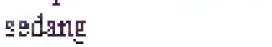 & 2 & gentang & 2 & \\
\hline luas & I & sulit & I & \\
\hline
\end{tabular}

Berdasarkan pertimbangan di atas, struktur tower yang cocok untuk penelitian ini adalah lattice tower. Hal ini dikarenakan material struktur tower lattice mudah didapat di wilayah Yogyakarta, biaya material dan pembuatan tower lebih murah, tempat produksinya tidak memerlukan lahan yang luas dan transportasi material dari tempat produksi ke tempat pemasangan relatif mudah. Dengan biaya pembuatan yang rendah, namun perlu ada tambahan biaya perawatan. tambahan biaya perawatan diperlukan untuk mempertahankan kemampuan dari tower maupun untuk inspeksi turbin angin. Kemudahan dalam hal perawatan merupakan salah satu pertimbangan didalam pemilihan konfigurasi. Besarnya biaya perawatan lattice tower relatif sama dengan jenis guyed, namun dari segi kemampuan tower jenis lattice lebih ungul. Jenis tubular memang memiliki kemampuan yang paling besar, karena mampu menopang turbin dengan diameter yang panjang (kapasitas pembangkit listik besar) namun dilihat dari tujuan penelitian ini, tower jenis ini tidak direkomendasikan. 
pemodelan strukturnya dilakukan dengan menggunakan bentuk konstruksi zig-zag dengan empat batang truss. Dimensi/ukuran tinggi tower adalah 10 meter dan lebar dasar konstruksi adalah 1.5 meter. Material yang digunakan untuk perancangan tower adalah steel jenis AISI 1018 (ST3).

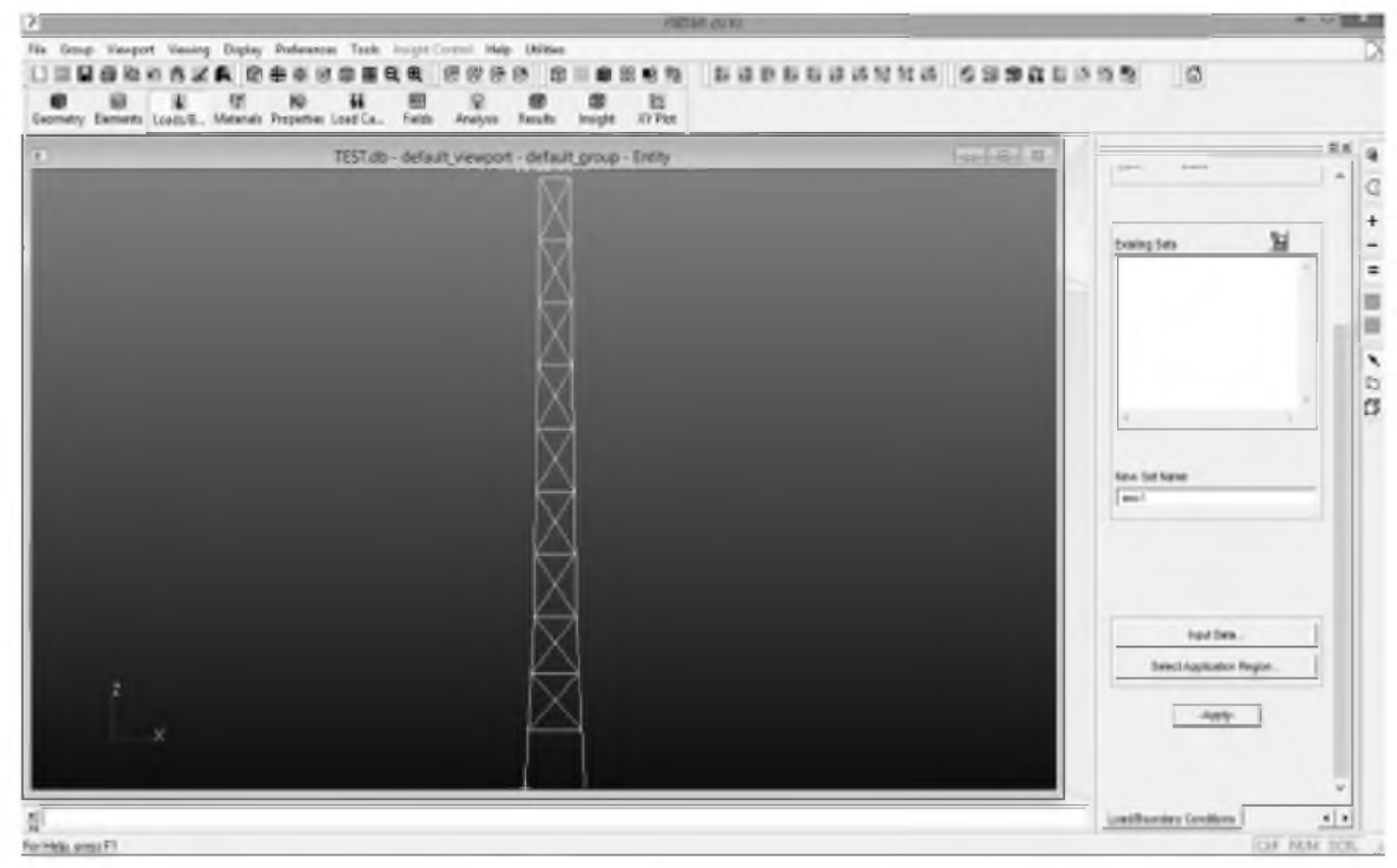

Gambar 2. Model tower

\section{Hasil dan Pembahasan}

Kasus pembebanan yang diterima oleh turbin angin bisa bervariasi tergantung letak dan kondisi dimana tower tersebut ditempatkan. Penelitian ini menggunakan 3 jenis beban yang akan digunakan untuk analisis tegangan.

\subsection{Beban akibat Thrust}

Persamaan yang dipakai dalam menghitung beban Thrust yaitu :

$$
T=C_{T_{2}}^{1} \rho \pi R^{2} v^{2}
$$

Di mana $\mathrm{T}$ adalah Thrust, $\rho$ adalah kerapatan udara, $\mathrm{v}$ adalah kecepatan aliran udara, dan $\mathrm{R}$ adalah panjang bilah.

$$
\begin{aligned}
\mathrm{T} & =2 \times 0,5 \times 1,212802 \times 3.14 \times 1.5^{2} \times 21.3^{2} \\
& =3889.391 \mathrm{~N}
\end{aligned}
$$

Dikarenakan ada terdapat 4 batang truss pada turbine angin jenis Lattice Tower, maka beban tersebut dibagi 4 : 
Hendrix Noviyanto Firmansyah, M Ardi cahyono

$$
\begin{aligned}
\mathrm{T} / 4 & =\frac{3805.391 \mathrm{~N}}{4} \\
& =972.347831 \mathrm{~N}
\end{aligned}
$$

\subsection{Beban Angin}

Beban angin yang dimaksud adalah beban terpaan aliran udara yang mengenai penampang struktur tower. Persamaan yang digunakan untuk mendapatkan beban angin ini adalah sebagai berikut :

$\mathrm{F}=\mathrm{AP} \mathrm{C} \mathrm{C}_{\mathrm{d}} \mathrm{K}_{\mathrm{h}}$

Contoh perhitungan beban akibat angin pada ketinggian 9,5 $\mathrm{m}$ dari permukaan tanah adalah sebagai berikut.

$\mathrm{F}=\mathrm{APC} \mathrm{C}_{\mathrm{d}} \mathrm{K}_{\mathrm{z}} \mathrm{G}_{\mathrm{h}}$

$=0.05 x \frac{1}{2} \times 1.212802 x 21.3^{2} \times 2.2 x \frac{9.5}{33}^{\frac{2}{7}} \times \frac{0.65+0.60}{\frac{9.5}{0.5}}$

$=28.981 \mathrm{~N}$

Tabel 4. Nilai beban angin

\begin{tabular}{|c|c|}
\hline Tinggi & Nilai Beban Angin \\
\hline $0.5 \mathrm{~m}$ & $15.922 \mathrm{~N}$ \\
\hline $1.5 \mathrm{~m}$ & $19.809 \mathrm{~N}$ \\
\hline $2.5 \mathrm{~m}$ & $21.971 \mathrm{~N}$ \\
\hline $3.5 \mathrm{~m}$ & $23.539 \mathrm{~N}$ \\
\hline $4.5 \mathrm{~m}$ & $24.793 \mathrm{~N}$ \\
\hline $5.5 \mathrm{~m}$ & $25.847 \mathrm{~N}$ \\
\hline $6.5 \mathrm{~m}$ & $26.763 \mathrm{~N}$ \\
\hline $7.5 \mathrm{~m}$ & $27.576 \mathrm{~N}$ \\
\hline $8.5 \mathrm{~m}$ & $28.310 \mathrm{~N}$ \\
\hline $9.5 \mathrm{~m}$ & $28.981 \mathrm{~N}$ \\
\hline
\end{tabular}

Nilai beban terhadap ketinggian dapat dilihat pada gambar 3 .

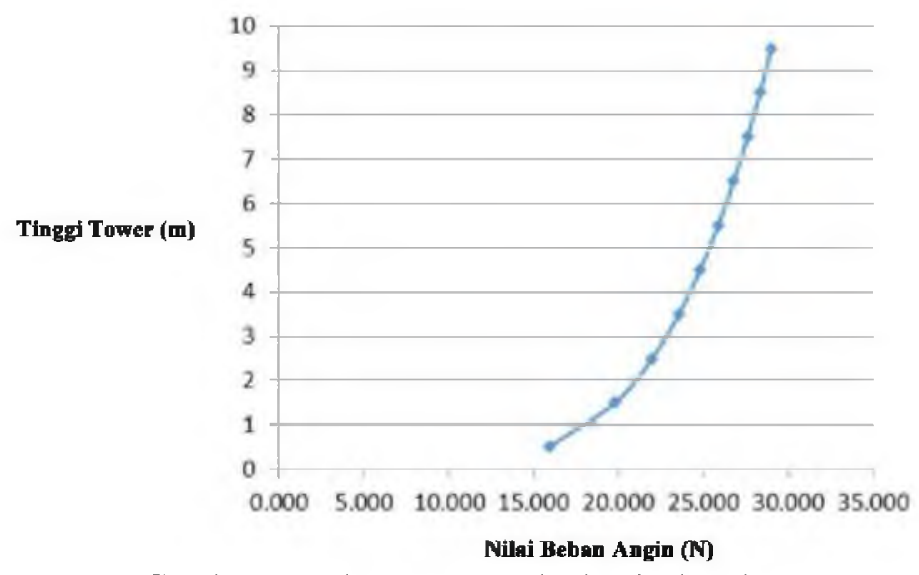

Gambar 3. Beban tower pada tiap ketinggian 


\subsection{Beban Mati}

a. Beban mati akibat kompen pendukung/asesoris.

Beban ini diasumsikan berat dari semua komponen pendukung/aksesoris seperti naccle, bilah, hub, dan lain sebagainya adalah tidak lebih dari $20 \mathrm{~kg}$. Maka untuk memudahkan dalam analisis nantinya, berat komponen pendukung/aksesoris sebesar 20 $\mathrm{kg}$ ini harus di ubahkah ke dalam satuan Newton.

$$
1 \mathrm{Kg}=9,81 \mathrm{~N}
$$

Maka, $20 \mathrm{Kg}=196,2 \mathrm{~N}$

Dikarenakan ada terdapat 4 batang thrust pada turbin angin jenis Lattice Tower, maka beban tersebut dibagi 4 :

$\frac{156,2 \mathrm{~N}}{4}=49,05 \mathrm{~N}$

Jadi pertitik 4 batang tersebut akan menerima beban kebawah sebesar 49,05 N.

b. Beban mati akibat berat dari struktur tower.

Juga sama dengan point a di atas, diasumsikan berat beban dari struktur tower itu sendiri diasumsikan $1 \mathrm{G}$.

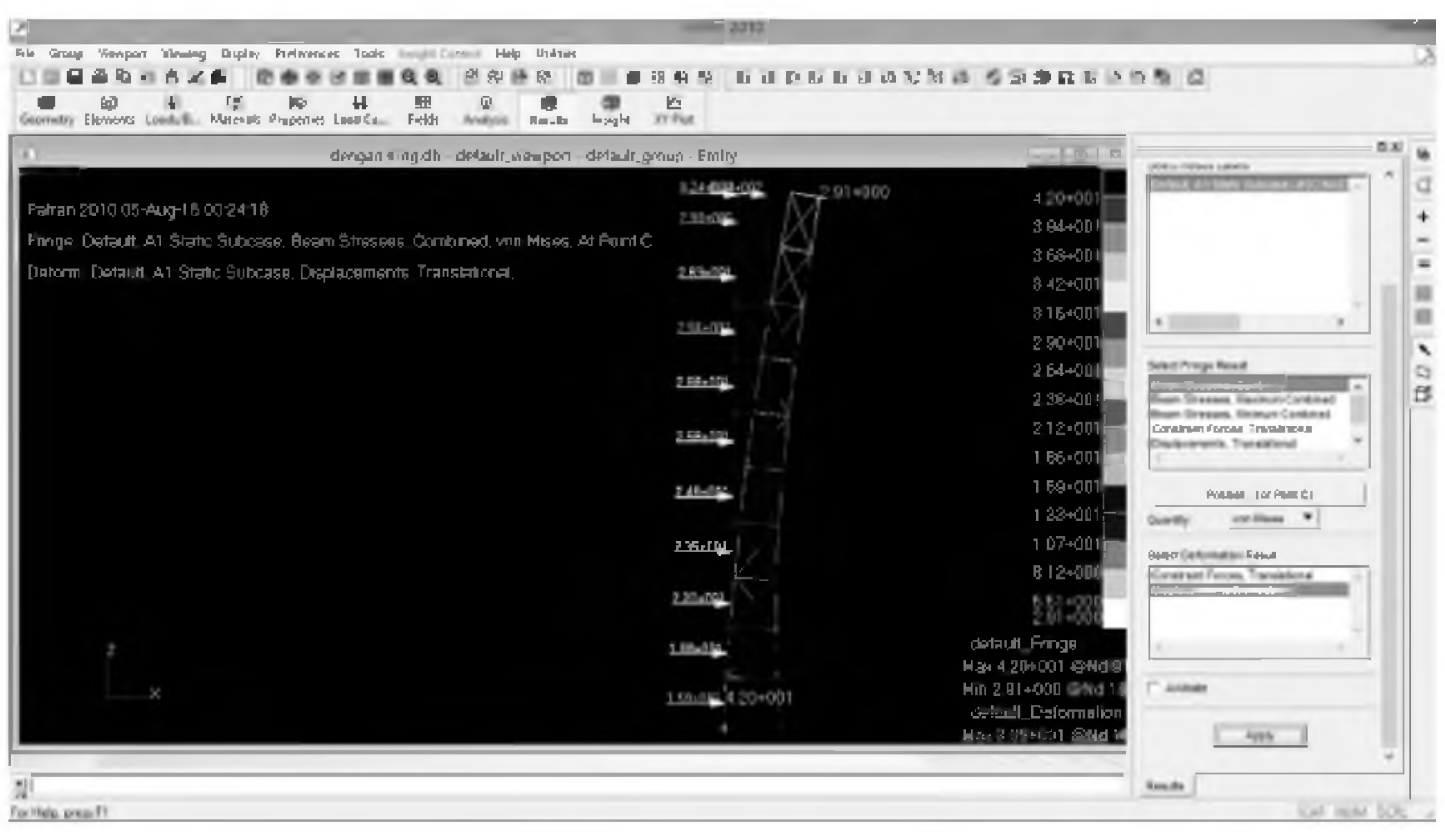

Gambar 4. Hasil Analisis

Hasil analisis menunjukkan tegangan maksimal yang terjadi sebesar $42 \mathrm{~N} / \mathrm{mm}^{2}$ dengan nilai MS sebesar 7.815 dan struktur dengan pembebanan tersebut aman. 


\subsection{Proses Pembuatan Bilah Komposit Sandwich}

Proses produksi dimulai dengan pembuatan master molding, cetakan, pembuatan core foam (isi), dan penggabungan sehingga menjadi bilah komposit sandwich (core foam). Hasil pembuatan 3 buah bilah komposit sandwich (core foam) menunjukkan hasil yang baik, biarpun terjadi perbedaan berat. Bilah 1 memiliki berat $2.245 \mathrm{~g}$, bilah 2 memiliki berat 2.215 g, dan berat bilah yang ke $32.165 \mathrm{~g}$.

Tabel 5. Perbandingan berat bilah

\begin{tabular}{|c|c|c|c|}
\hline Bilah & $\begin{array}{c}\text { Berat } \\
(\mathrm{g})\end{array}$ & $\begin{array}{c}\text { Berat } \\
(\mathrm{g})\end{array}$ & $\%$ \\
\hline 1 & 2.245 & 0 & 0 \\
\hline 2 & 2.215 & 30 & -1.3363 \\
\hline & & & - \\
3 & 2.165 & 80 & 3.56347 \\
\hline
\end{tabular}

Perbedaan terjadi karena pengerjaan masih manual sehingga dirasa perbedaan tersebut masih dimaklumi.

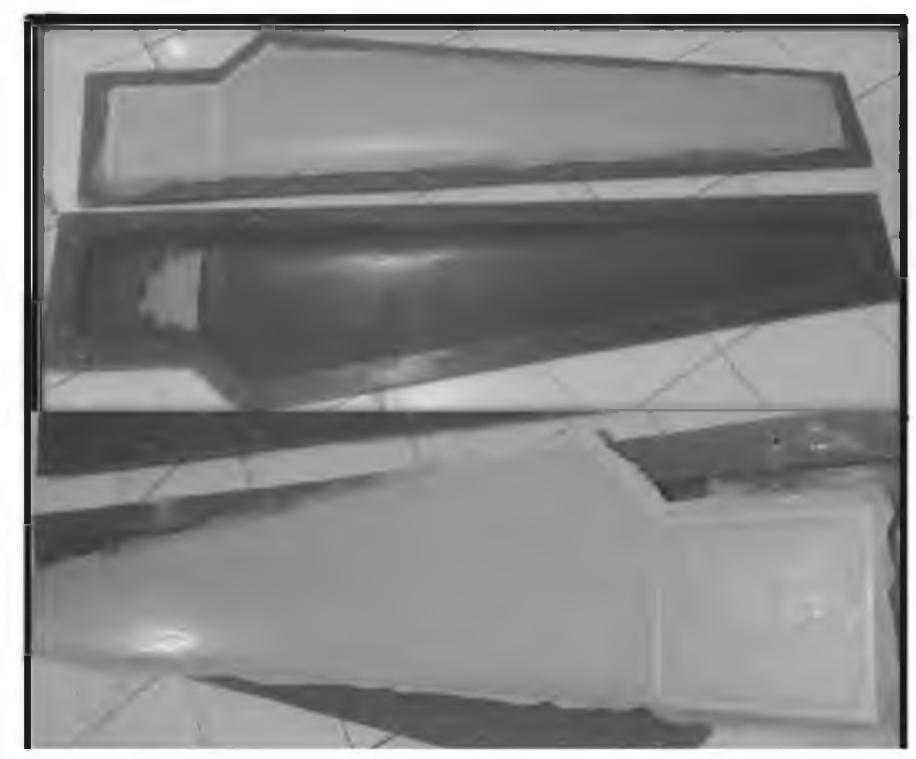

Gambar 5. Bilah hasil cetakan

\section{Kesimpulan}

Kesimpulan yang bisa didapat dari penelitian ini adalah sebagai berikut:

1. Konfigurasi tower yang diusulkan adalah jenis lattice. Kenfigurasi tersebut didasarkan atas biaya yang murah, kemudahan dalam perawatan, kemampuan mensupport turbin yang cukup, lahan yang digunakan sedikit (sempit) dan proses pembuatan dan transportasi yang mudah. 
2. Konfigurasi yang digunakan adalah tipe persegi (tower dengan empat batang pondasi memiliki panjang yang sama). Konfigurasi empat kaki memiliki kekakuan dan kekuatan yang baik jika dibandingkan dengan jenis triangle dan pole. Konfigurasi ini adalah tipe konvensional dan banyak digunakan sebagai tower turbin angin maupun listrik. Tinggi tower ini adalah $10 \mathrm{~m}$ dengan jarak beam pondasi $1.5 \mathrm{~m}$. Hasil analisis menunjukkan tegangan maksimal yang terjadi sebesar $42 \mathrm{~N} / \mathrm{mm}^{2}$ dengan nilai MS sebesar 7.815 dan struktur dengan pembebanan tersebut aman.

3. Proses pembuatan bilah dilakukan dengan mempersiapkan semua alat dan bahan. Persiapan diperhatiakan untuk kelancaran proses produksi. Proses produksi dimulai dengan pembuatan master molding, cetakan, pembuatan core foam (isi), dan penggabungan sehingga menjadi bilah komposit sandwich (core foam). Hasil ketiga bilah yang dibuat menunjukkan adanya perbedaan berat. Perbedaan tersebut dikarenakan sistem pembuatan yang masih manual. Namun perbedaan yang dihasilkan masih relevan atau baik karena persentase berat bilah kurang dari 5\%. 


\section{Daftar Pustaka}

Amara, I., 2014, Desain Proses Produksi Untuk 3 Bilah Turbin Angin Komposit, Sekolah Tinggi Teknologi Adisutjipto, Yogyakarta.

Anderson, John D., 2007, Fundamentals of Aerodynamics (4th ed.). McGraw-Hill.

Burton, Tony., Sharpe, David., Jenkins, Nick., Bossanyi, Ervin, 2001, Wind Energy Handbook. John Wiley \& Sons Ltd.

Corbert Nicholson, 2011, Effect of dust on the performance of wind turbines.

Desalination, 2007, pp. 209-220.

Cracks, 2012, Wind Energy system: Electronic edition. Manhattan.

Erinofiardi, Hendra, 2012, Analisa Defleksi Struktur Tower Transmisi Menggunakan Metode Elemen Hingga, Jurusan Mesin Fakultas Teknik Universitas Bengkulu, Bengkulu.

Ginting, Paham dan Syafrizal Helmi Situmorang, 2008, Filsafat Ilmu dan Metode Riset, USU Press, Medan.

Jamil Fahad, 2008, Jenis Struktur Tower Turbin Angin, Jakarta.

Hansen, Martin O. L., 2008, Aerodynamics of wind turbines, $2^{\text {nd }}$ edition. Earthscan.

Lavassas I, Nikolaidis G, Zervas P, Baniotopoulos CC, Doudoumis IN., 2002, Analysis and design of the $1 \mathrm{MW}$ steel wind turbine towers at mount Kalogerovouni Lakonia, Proc. 4th Nat. Conf. on Steel Structures Patras 2002, p. 272-280.

Huskey A, Prascher D., 2005, Tower Design Load Verification on a 1-kW Wind Turbine. To be presented at the 43rd AIAA Aerospace Sciences Meeting and Exhibit Reno. Nevada January 10-13. 2005

M Hani, Negm, Y Karam. Maalawi., 2000, Structural design optimization of wind turbine towers. Computers and Structures 74. page $649-666$.

Jamil, Fahad, Saad, bin zia, Abbasi, Parvez ali, Ansari, Moiz., 2012, To Study Of Wind Resistant Stability of Tubular Wind Turbine Tower. NED University of Engineering \& Technology.

Sukmadinata, NS., 2007, Metode Dalam Penelitian, Yudhistira, Jakarta.

Sumargo, Achmad Djihad, Iwan Setiawan, Dudi Arief Mulyadi, 2008, Analisa Respon Struktur Menara Pemancar Tipe "Monopole" 120 M Akibat Beban Angin Rencana Dengan Periode Ulang 10 Tahunan Di Stasiun Badan Meteorologi Dan Geofisika Semarang, Jurnal Teknik Sipil Volume VIII Nomor 1, Semarang.

$\mathrm{http} / / / \mathrm{k} 7 \mathrm{nv} . \mathrm{com} /$ notebook/topics/windload.html. 